Research Article

\title{
Seismic Behavior of Rammed Earth Walls with Precast Concrete Tie Columns
}

\author{
Xinlei Yang $\mathbb{D}^{1,2}$ and Hailiang Wang ${ }^{1,2}$ \\ ${ }^{1}$ School of Civil Engineering, Tianjin Chengjian University, No. 26, Jinjing Road, Xiqing District, Tianjin 300384, China \\ ${ }^{2}$ Tianjin Key Laboratory of Civil Buildings Protection and Reinforcement, No. 26, Jinjing Road, Xiqing District, \\ Tianjin 300384, China
}

Correspondence should be addressed to Xinlei Yang; yxl@tcu.edu.cn

Received 3 December 2017; Accepted 30 January 2018; Published 13 March 2018

Academic Editor: Robert Cerný

Copyright (c) 2018 Xinlei Yang and Hailiang Wang. This is an open access article distributed under the Creative Commons Attribution License, which permits unrestricted use, distribution, and reproduction in any medium, provided the original work is properly cited.

\begin{abstract}
Rammed earth (RE) constructions are widespread in underdeveloped rural areas in developing countries. However, these RE constructions are often susceptible to earthquake damage due to their poor seismic performance. Precast concrete tie columns and ring beam (tie bars) were proposed to improve the seismic behavior of RE constructions. Four RE walls, including a traditional RE wall and three RE walls with precast concrete tie columns and ring beam (tie bars), were tested under reversed cyclic loading, and the seismic behavior of these tested specimens was evaluated in terms of failure pattern, energy dissipation, displacement ductility, and stiffness degradation. The results showed that a significant increase of the load-bearing and deformation capacity could be achieved with the application of precast concrete tie columns in combination with RE. The load-bearing capacity and deformation capacity of traditional RE wall were increased by an average of $113 \%$ and $417 \%$, respectively. These test results could provide reference to the design and construction of the environmental-friendly structures in rural areas.
\end{abstract}

\section{Introduction}

Rammed earth (RE) dwellings are widespread in underdeveloped rural areas of western China, which has several advantages over other buildings, including low cost, easy availability, thermal comfort, and low intervention with surroundings. However, RE constructions have drawbacks of sensitivity to water, propensity to shear failure, and lacking systemic engineering design concerning earthquake. They are susceptible to earthquake damage owing to low compressive strength, shear strength, and durability [1-5].

Many efforts have been undertaken to enhance the mechanical properties of rammed earth. Niroumand et al. [6] investigated the influence of nanotechnology on material characteristics of rammed earth, and the results showed that nanoclay could increase the level of compressive strength in rammed earth walls and be used as a cohesive material in the soil mixture. Venkatarama Reddy and Prasanna Kumar [7] studied the relationship among soil density, moisture content, and compressive strength and found that the compressive strength of rammed earth was very sensitive to its dry density and moisture content. Cheah et al. [8] conducted an experimental study of the shear strength of a stabilized RE material reinforced with sisal and flax fibres. The results showed that a shear failure of the triplet test appeared along the weak interface between layers, but specimens failed along diagonal shear plane at the triaxial test. Bouhicha et al. [9] conducted a study to investigate the influence of fibre length and fibre fraction on compressive strength, flexural strength, and shear strength of rammed earth. The results proved that adding straw could decrease shrinkage damage, reduce the curing time, and improve the mechanical property. Bui et al. [10] analyzed the role of the moisture content on the mechanical characteristics and illuminated the importance of suction to RE specimens. There are limited numbers of studies on the improvement of the performance of rammed earth buildings using various reinforcement technologies. Bu et al. [11] studied the effect of 
the split-level construction or pin keys on shear strength of rammed earth walls and found that the two methods were effective in improving the shear strength of construction with respect to the traditional method.

Generally, many experimental investigations have been conducted to enhance the mechanical properties of rammed earth by improvements in material characterization (chemical, physical, mechanical, and durability) and possible additions (lime, cement, straws, and fibres). However, there are limited investigations addressing the issues of the attempt to enhance seismic performance of rammed earth buildings by means of structural strengthening solutions. In this paper, precast concrete tie columns and precast concrete tie beam (tie bar) were proposed to improve the seismic behavior of RE constructions, and the effectiveness of these structural strengthening solutions is validated by conducting cyclic loading tests. The test results could provide data to support the RE construction practices.

\section{Materials and Methods}

2.1. Materials. In this study, the used soil was taken from Gongyi County in Henan Province, China, which is located in the East Loess Plateau. The properties of selected soil are outlined in Table 1. Generally, compaction characteristics of rammed earth are evaluated by two important parameters, that is, optimum moisture content (OMC) and maximum dry density (MDD). By the standard Proctor tests, OMC is $16.5 \%$ and MDD is $1710 \mathrm{~kg} / \mathrm{m}^{3}$.

In view of the availability, economy, and ease of construction, cement was selected as a stabilizer. Ordinary Portland cement of 42.5 grade was used in the experimental investigations. In the experimental investigations, $10 \% \mathrm{ce}$ ment by dry mass of soil was used for production of test specimens. In the test specimens, the diameter of corrosion resistant zinc-coated wire used as tie bars is $2.6 \mathrm{~mm}$. Table 2 summarizes the properties of the steel bars. During the construction of each wall, $150 \times 150 \times 150 \mathrm{~mm}$ cubes were prepared to test compressive strength of cement-stabilized rammed earth (CSRE). The average compressive strength was in the range of $4.5 \sim 8.4 \mathrm{MPa}$.

2.2. Specimen Design and Construction. This research conducted experimental investigations on four 1/3-scale $1600 \times 1200 \times 200 \mathrm{~mm}(L \times H \times W) \mathrm{RE}$ walls under lateral cyclic loading; considering the requirement of loading equipment, the height is $1400 \mathrm{~mm}$ actually. The dimensions and reinforcement details of the tested specimens are shown in Figure 1.

Specimen Q-1 was designed as a traditional CSRE wall without tie columns and tie beam (tie bar) and used as a control specimen, as shown in Figure 1(a). Specimen K-1 was designed as a frame, which consisted of a precast concrete tie beam and two concrete tie columns, as shown in Figure 1(b). The other three specimens were CSRE walls with the precast concrete tie columns, and those tie columns had the same dimensions and reinforcement details. Structural characteristics of each tested specimen are briefly summarized in Table 3.
TABLE 1: Summary of soil properties.

\begin{tabular}{lcc}
\hline Property & Parameters & Value \\
\hline \multirow{3}{*}{ Grain size distribution } & Gravel fraction & $28 \%$ \\
& Sand fraction & $44 \%$ \\
& Silt fraction & $13 \%$ \\
Atterberg limit & Clay fraction & $15 \%$ \\
& Liquid limit & $27.8 \%$ \\
Proctor test & Plastic limit & $17.7 \%$ \\
& Plastic index & $10.1 \%$ \\
& Optimum moisture content & $16.5 \%$ \\
& Maximum dry density $\left(\mathrm{kg} / \mathrm{m}^{3}\right)$ & 1710 \\
\hline
\end{tabular}

TABLe 2: Mechanical properties of reinforcing bars.

\begin{tabular}{lcccc}
\hline $\begin{array}{l}\text { Bar } \\
\text { type }\end{array}$ & $\begin{array}{c}\text { Yield } \\
\text { strength } \\
(\mathrm{MPa})\end{array}$ & $\begin{array}{c}\text { Ultimate tensile } \\
\text { strength }(\mathrm{MPa})\end{array}$ & $\begin{array}{c}\text { Elastic } \\
\text { modulus } \\
(\mathrm{GPa})\end{array}$ & $\begin{array}{c}\text { Ultimate } \\
\text { elongation } \\
(\%)\end{array}$ \\
\hline$\Phi 6$ & 356 & 418 & 202 & 22.4 \\
$\Phi 2.6$ & 352 & 435 & 202 & 15.4 \\
$\Phi 2$ & 321 & 403 & 186 & 14.2 \\
\hline
\end{tabular}

Specimen Q-2 was designed as a reinforced CSRE wall with a precast concrete tie beam and two concrete tie columns, as shown in Figure 1(c). Specimen Q-5 is similar to Specimen Q-2; however, one wire tie is used instead of the precast concrete tie beam, as shown in Figure 1(d). Specimen Q-7 was designed as a reinforced CSRE wall with two precast concrete tie columns and three wire ties starting at $400 \mathrm{~mm}$ from the top of the foundation beam that were spaced at $400 \mathrm{~mm}$ along the wall height, as shown in Figure 1(e). In order to prevent slippage between the CSRE wall and the steel ground beam, two rows of bolts were installed on the surface of footing and performed well as expected.

Using precast concrete tie columns and tie beam could avoid negative effects of moisture on strength of CSRE. The precast concrete tie columns and tie beam had the dimensions of $80 \mathrm{~mm} \times 80 \mathrm{~mm} \times 1400 \mathrm{~mm}$ and $80 \mathrm{~mm} \times 80 \mathrm{~mm} \times 1440 \mathrm{~mm}$, respectively, and were constructed using C30 concrete. The longitudinal reinforcement used in the precast concrete column was four $\Phi 6$ plain bars, and the transverse reinforcement was $\Phi 2$ galvanized iron wire. The longitudinal reinforcement of precast concrete tie beam was four $\Phi 6$ plain bars, and the transverse reinforcement was $\Phi 2$ galvanized iron wire. The dimensions and reinforcement details are shown in Figure 2.

The soil was prepared to their optimum moisture content determined by the compaction test and compacted inside aluminum alloy I-beam molds to form walls. The test wall is composed of several layers of earth and constructed on a steel ground beam. The earth was poured into molds in layers approximately $350 \mathrm{~mm}$ thick and then compacted with a pneumatic compactor rammer. The thickness of each layer after compaction maintained roughly at $200 \mathrm{~mm}$. In order to guarantee the cohesiveness between layers, compacting in corners and spraying water at each layer surface were accomplished manually. 


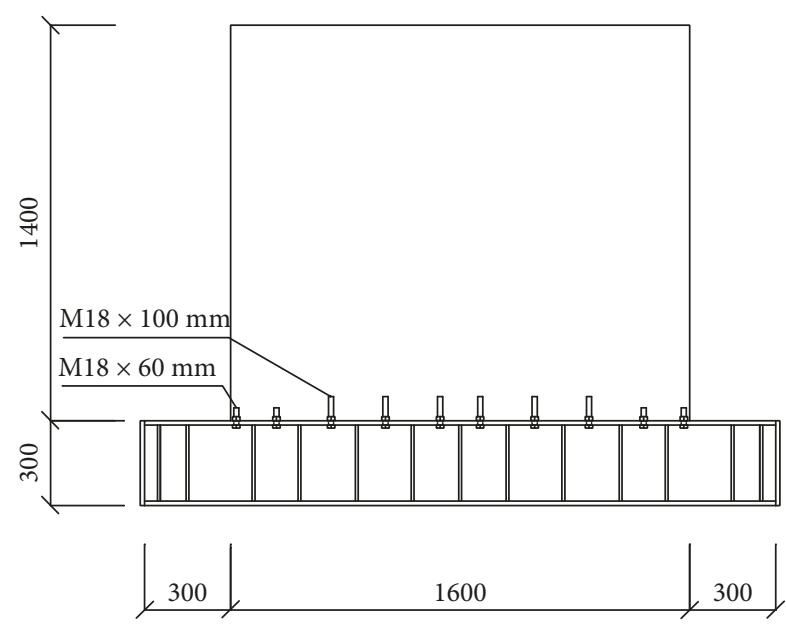

(a)

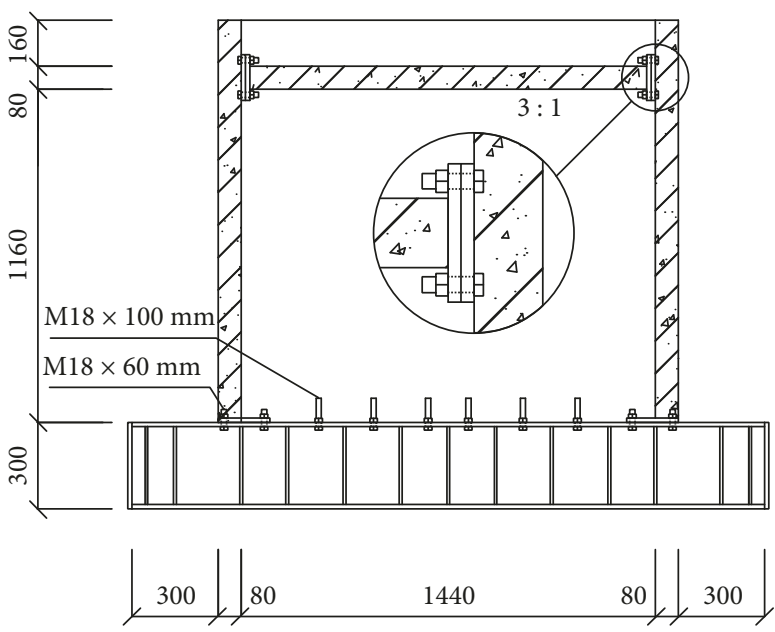

(c)

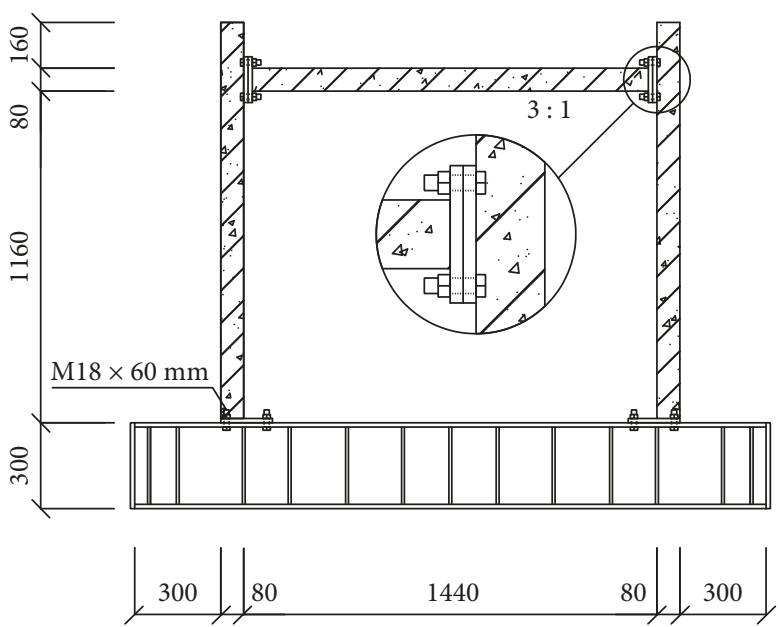

(b)

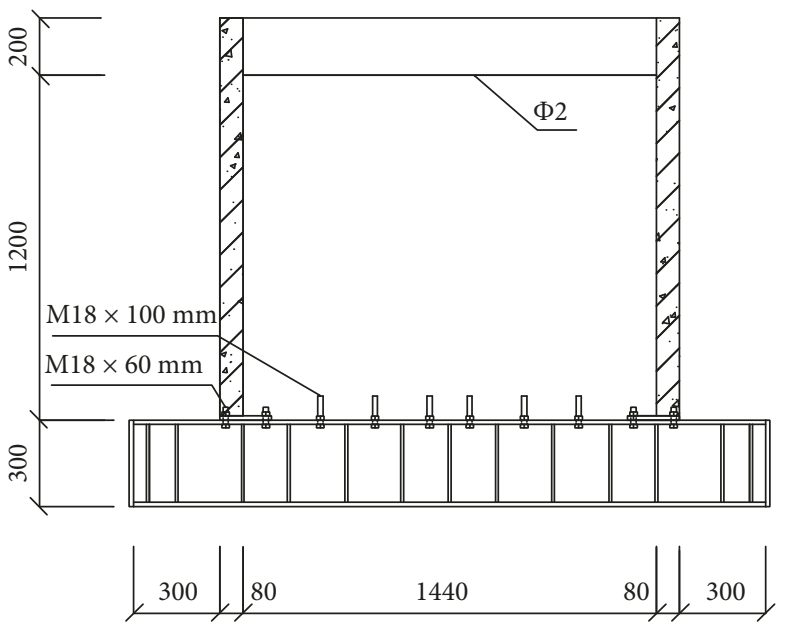

(d)

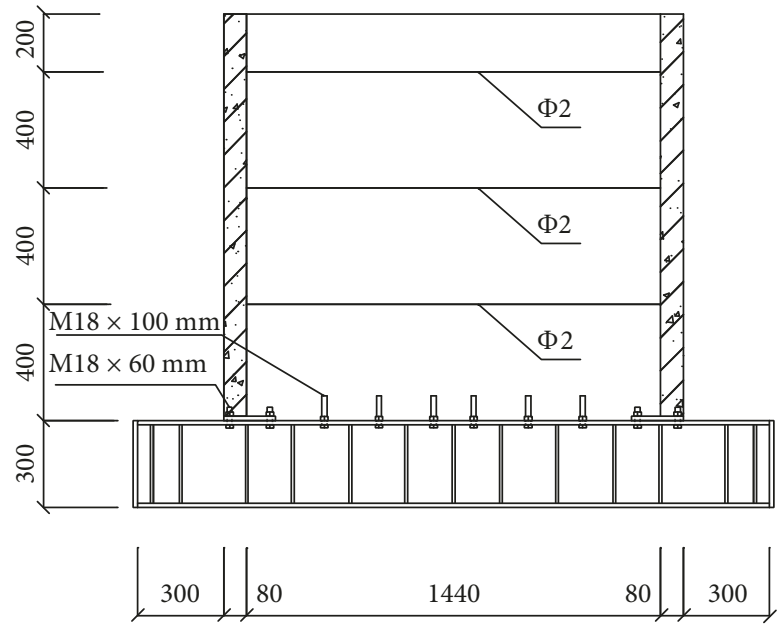

(e)

Figure 1: Dimensions and details of test specimens (unit: mm). (a) Q-1. (b) K-1. (c) Q-2. (d) Q-5. (e) Q-7.

2.3. Test Setup and Instrumentation. A servohydraulic actuator with $150 \mathrm{kN}$ maximum load and a $\pm 250 \mathrm{~mm}$ displacement range was used to apply a quasistatic lateral loading to $1200 \mathrm{~mm}$ height in two opposite directions. A hydraulic jack was used to carry out a constant axial load to the top of the wall to simulate gravity actions. Specimen K-1 was only subjected to horizontal reversed cyclic loading without the vertical load. The loading devices and 
TABLE 3: Summary of structural characteristics of the tested specimens.

\begin{tabular}{lcc}
\hline Specimen & Structural characteristics & Remarks \\
\hline Q-1 & Without tie columns & Control specimen \\
K-1 & Precast concrete tie columns + precast concrete tie beam & Precast concrete tie columns + precast concrete tie beam + CSRE \\
Q-2 & Precast concrete tie columns + one wire tie + CSRE \\
Q-5 & Precast concrete tie columns + three wire ties + CSRE \\
Q-7 &
\end{tabular}

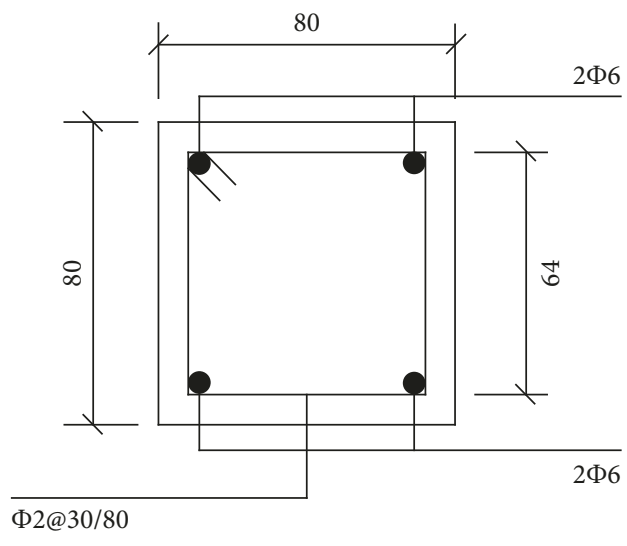

(a)

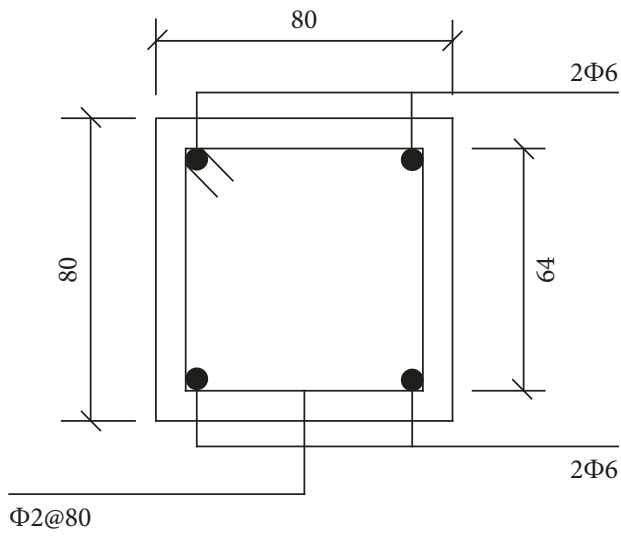

(b)

Figure 2: Details of the precast concrete tie column (a) and tie beam (b).

the site of test setup are shown in Figures 3 and 4, respectively.

For each test wall, a total of five displacement sensors were used to record the displacement developed at different loading stages, as shown in Figure 5. Displacement of the ground beam relative to strong floor was measured by number $D_{0}$. Displacement of the ground beam relative to wall was measured by number $D_{3}$. Lateral displacement of wall was measured by numbers $D_{1}$ and $D_{2}$, which were installed at loading position centerline. The diagonal strain of the wall is recorded by numbers $D_{4}$ and $D_{5}$, which were positioned in the diagonal direction.

2.4. Test Procedure and Loading Characteristics. A constant axial load of $26.43 \mathrm{kN}$ simulated to gravity actions was applied to the wall and was maintained constant throughout each test. The applied axial load at the top of the walls includes the dead loads (self-weights of the roof and wall) and the live load $\left(0.5 \mathrm{kN} / \mathrm{m}^{2}\right)$, which was defined by the similitude law. It represents a normal stress of $0.08 \mathrm{MPa}$, as in current rammed earth walls in a one storey house in China.

After application of the axial load to the top of the steel beam, low-rate lateral cyclic loading of increasing amplitudesimulated lateral earthquake loading was applied to a height of $1200 \mathrm{~mm}$. The test walls were loaded in a displacement- (drift-) controlled mode at a constant rate of $0.2 \mathrm{~mm} / \mathrm{s}$, and two fully reversed cycles were applied at each drift. The selected drift was intended to cause displacements that investigated inelastic deformations of the wall corresponding to earthquake action.

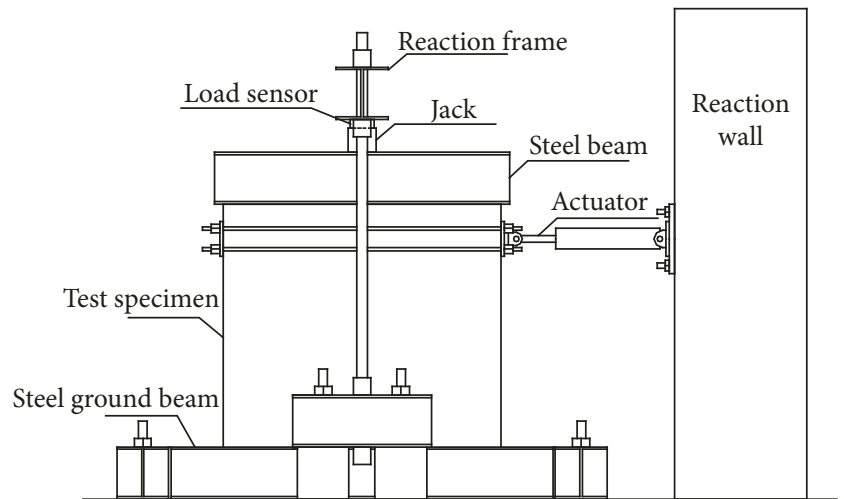

FIGURE 3: The schematic drawing of loading devices.

Each test was initiated at interval steps of $0.1 \%$ drift ratios until $0.8 \%$. In the range of $0.8 \% \sim 2 \%$ drift ratios, the specimen was cycled at interval steps of $0.2 \%$. In the range of $2 \% \sim 4 \% \mathrm{drift}$ ratios, the specimen was cycled at interval steps of $0.4 \%$. When the drift ratios reached $4 \%$, interval steps of $0.8 \%$ drift ratios were imposed to the specimens until failure or instability. The lateral cyclic loading protocol is shown in Figure 6.

\section{Failure Process and Modes}

The final failure modes of tested specimens observed are shown in Figure 7.

Specimen Q-1: the damage was initiated at a drift ratio of approximately $0.2 \%$, at which time the first horizontal crack appeared at a distance of $230 \mathrm{~mm}$ from the bottom of the wall. The horizontal crack propagated in 


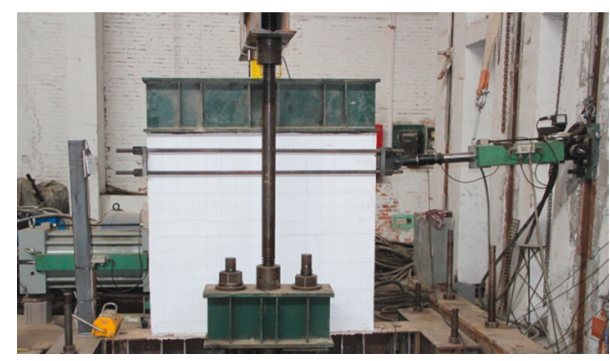

Figure 4: The picture of the test setup.

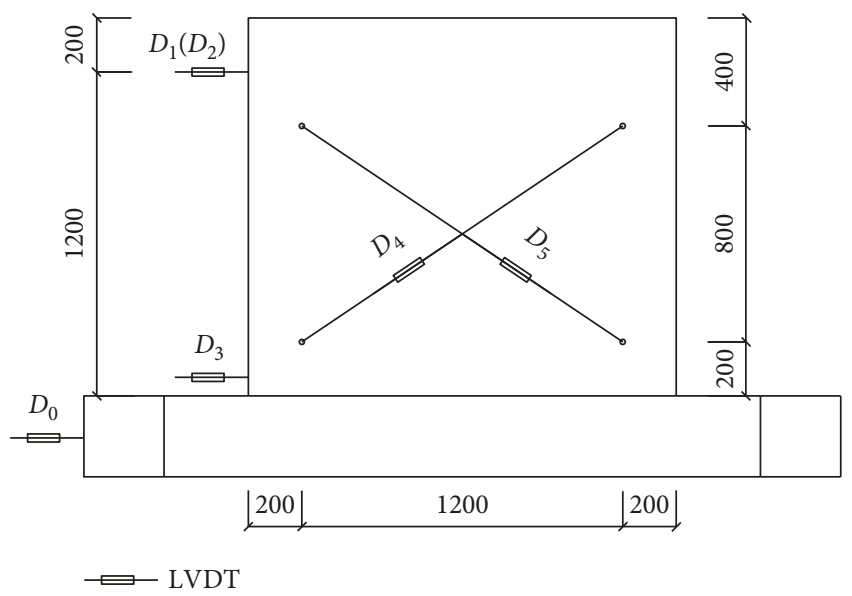

FIgURE 5: Measurement layout of instrumentation.

size and evolved into a horizontal penetrating crack at $0.3 \%$ drift ratio. As the drift increased, the wall was separated into two portions by this horizontal penetrating crack, and the relative slippage was observed at a drift ration of $0.8 \%$. The cracking patterns of Specimen Q-1 are shown in Figure 7(a).

Specimen Q-2: a horizontal shrinkage crack forming at $200 \mathrm{~mm}$ below the loading position evolved into a horizontal penetrating crack at a drift of approximately $0.2 \%$. When increasing displacement in both the positive and negative directions, the horizontal cracks propagated to both sides of the columns and local shear failure was observed on columns at a drift of approximately $2.4 \%$. The ultimate failure mode refers to Figure $7(\mathrm{~b})$.

Specimen Q-5: a horizontal shrinkage crack at the central region of the wall evolved into a penetrating crack at a drift ratio of $0.1 \%$, and horizontal cracks occurred on both sides of tie columns at a drift ratio of $0.8 \%$. The test was stopped at $6.4 \%$ drift ratio, and at the end of the test, the bearing capacity was not reduced except for the presence of out-of-plane displacements of the wall. The ultimate failure of the wall refers to Figure 7(c).

Specimen Q-7: in the middle section of the wall, a horizontal shrinkage crack penetrated into wall core at a drift of $0.2 \%$ and the crack width increased remarkably as the drift increased. Flexural cracks emerged on both sides of precast concrete tie columns at a drift ratio of

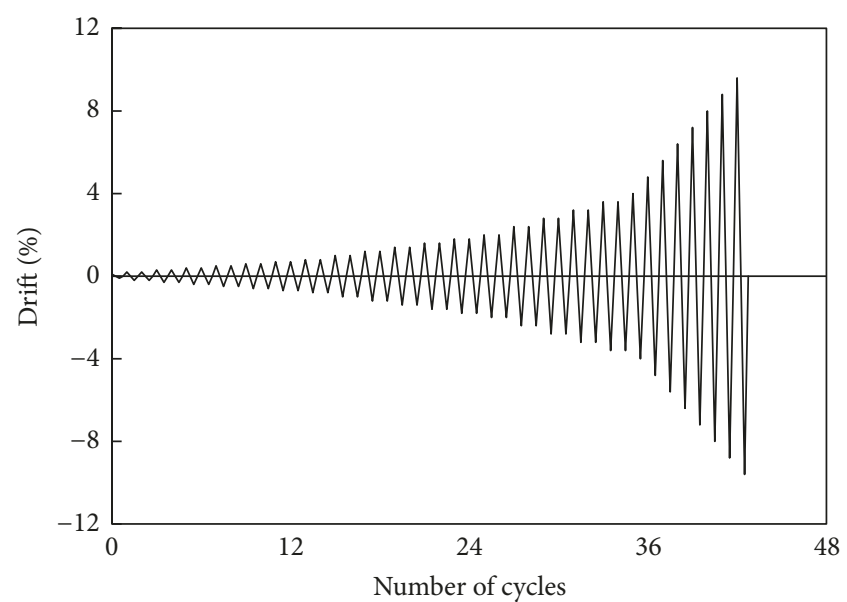

Figure 6: Loading history.

$0.6 \%$. Specimen Q-7 was loaded at increasing drift until $9.6 \%$, at which time the test was terminated because of out-of-plane displacements of the wall. The ultimate failure mode refers to Figure $7(\mathrm{~d})$.

Specimen K-1: the flexural cracks of Specimen K-1 were observed on both ends of columns at a drift ratio of $0.4 \%$ and propagated gradually along the height with the drift increasing. The concrete in the joint region spalled and crushed off at a drift ratio of 9.6\%. Additionally, the column longitudinal reinforcement exposed progressed. The ultimate failure mode refers to Figure $7(\mathrm{e})$.

It could be seen from Figure 7 that the failure modes of these wall specimens were dominated by a shear failure mechanism. The horizontal penetrating cracks were mainly formed along a layer interface, illustrating that the layer interface is the weak regions in rammed earth walls. For Specimen Q-2, the earth under the precast concrete tie beam was not compacted to be very dense due to space constraints and formed a weak region, which causes the local failure appearing on both sides of precast concrete tie columns ahead of expected theoretical design attributed to uneven distributed load. The performance of Specimen Q-5 is similar to that of Specimen Q-7, in terms of crack development and reduction process of bearing capacity, respectively. With increasing drift amplitudes, the confinement effect exerted by precast concrete tie columns and wire ties gradually played a role and the load-bearing capacity of tested specimens increased slowly. Although the load had dropped to $85 \%$ below the peak value, the increase of strength at late stage of loading can be regarded as capacity reservation.

\section{Results and Discussion}

4.1. Overall Response. The hysteresis curves are the most important characteristic for assessing the seismic performance of tested walls under cyclic loading in terms of the energy dissipation capacity, the ductility performance, strength deterioration, and stiffness degradation of the wall. The hysteresis 


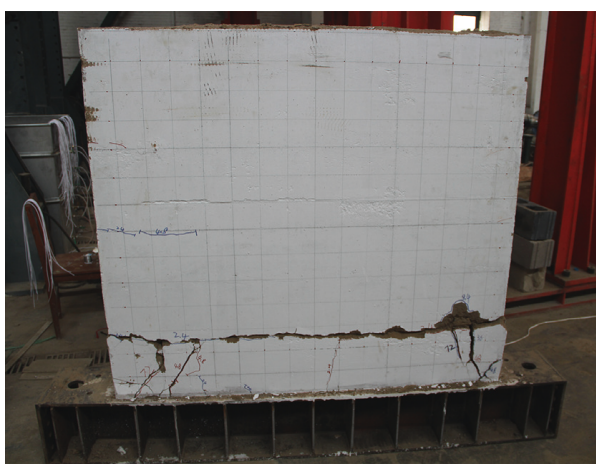

(a)

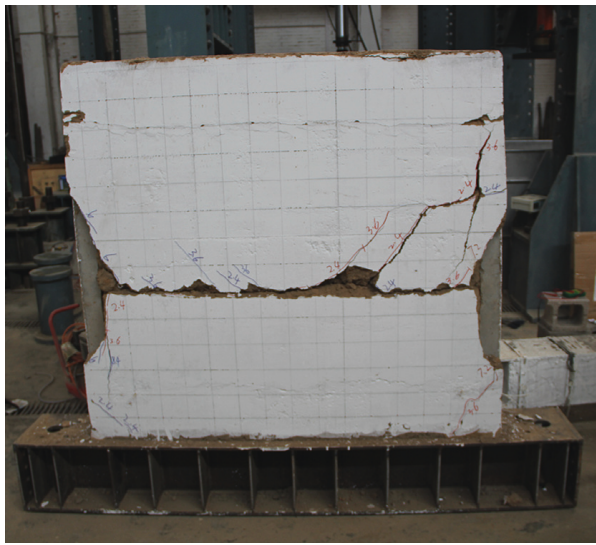

(c)

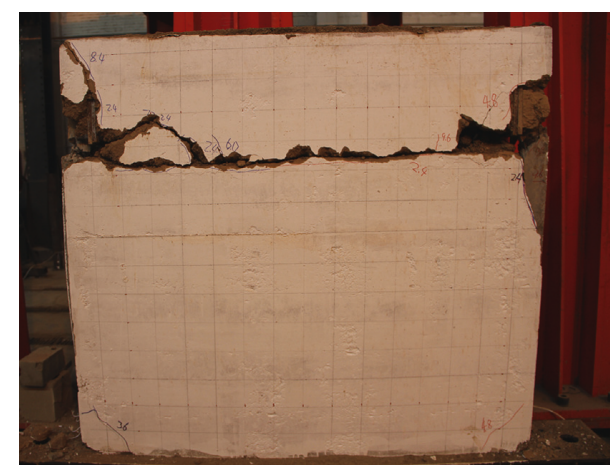

(b)

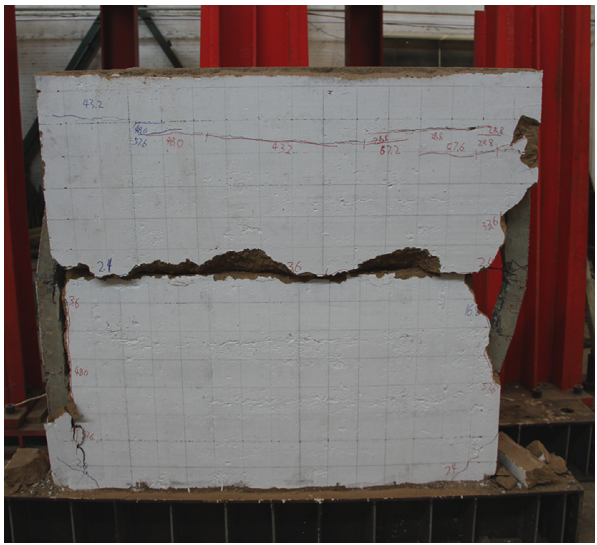

(d)

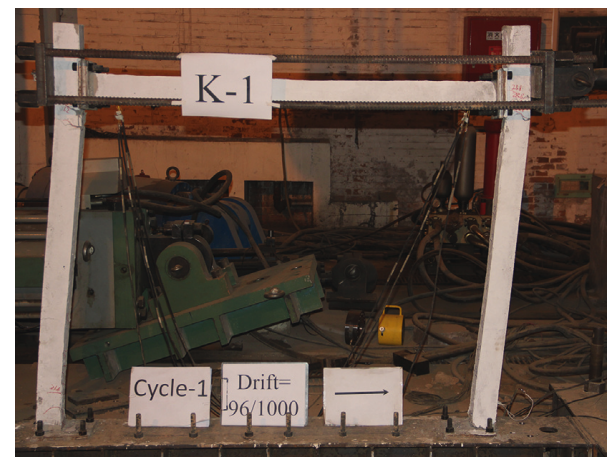

(e)

Figure 7: Failure mode of tested specimens. (a) Specimen Q-1. (b) Specimen Q-2. (c) Specimen Q-5. (d) Specimen Q-7. (e) Specimen K-1.

loops (load versus story drift) of four test specimens are presented in Figure 8.

It could be seen that Specimen Q-1, as a control specimen, exhibited poor hysteretic properties with a remarkable strength drop after peak load, with this unfavorable performance attributed to lack of precast concrete tie columns in the wall. Other three wall specimens with precast concrete tie columns exhibited a stable lateral load versus drift hysteretic response, especially Specimens Q-5 and Q-7, showing that the seismic performance of rammed earth walls can considerably be improved through the use of precast concrete tie columns and wire ties.

The hysteresis loops of specimen Q-2, Q-5, and Q-7 presented a fusiform shape during initial loading. With increasing cracks, and after spalling and crushing of earth, the curve shape gradually changed into reverse $S$, which illustrated that cracks progressed adequately so that impossible to recover and residual deformations appeared in the later stage.

The ability of a structure to survive an earthquake depends to a large extent on its ability to dissipate the input energy. The good energy dissipation capacity indicates the capacity of the structure to perform satisfactorily in the inelastic range. The amount of cumulative energy dissipated is plotted versus the roof drift in Figure 9. The energy dissipation capacity of Specimen K-1 is significantly inferior to other three specimens at the same drift, which illustrates that the rammed earth plays a major role in energy dissipation capacity. After comparison of Specimen Q-1 and other three walls, it could be found that the cowork between 


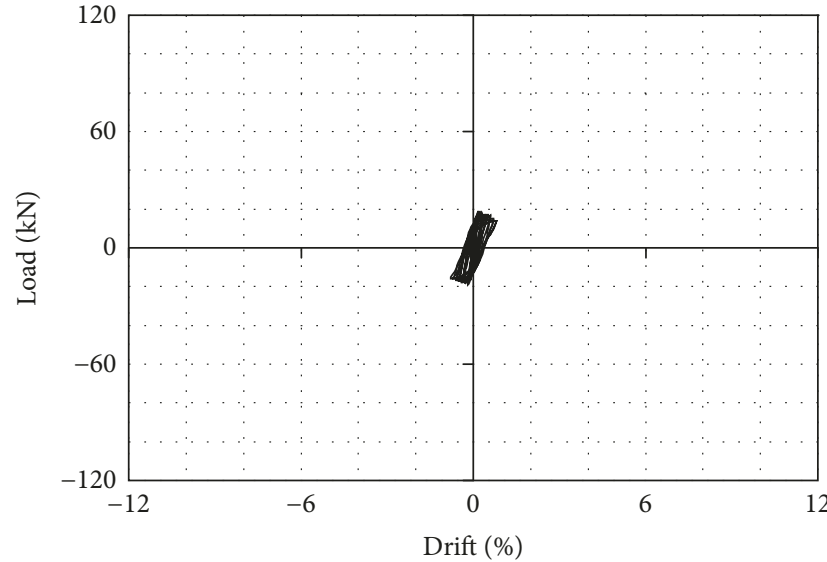

(a)

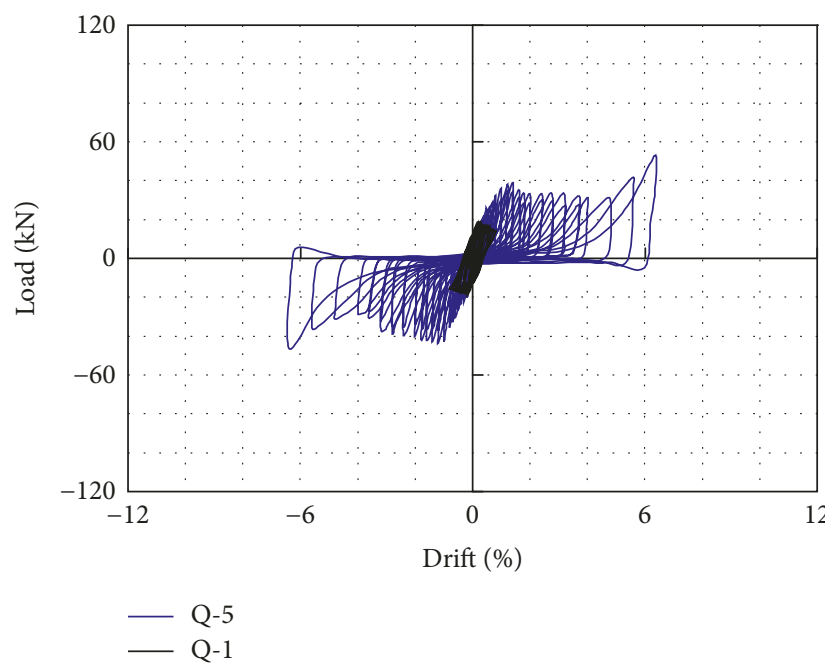

(c)

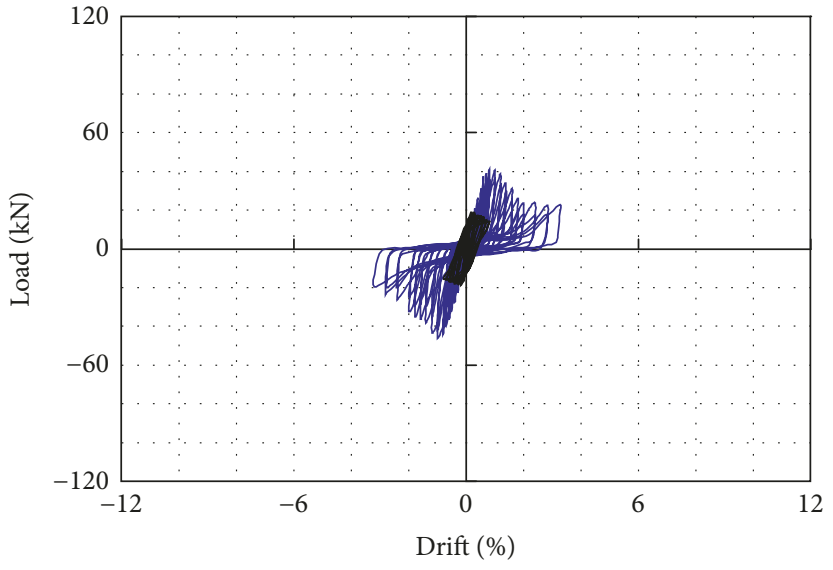

- Q-2

(b)

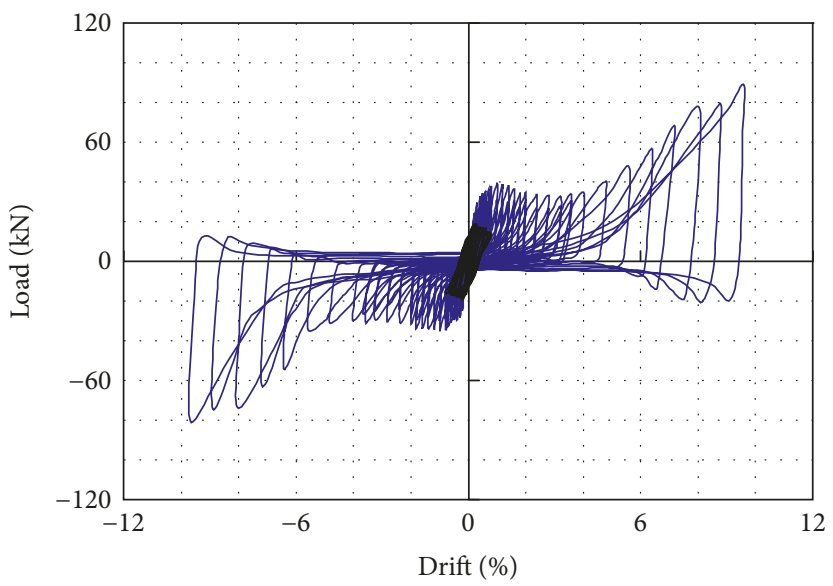

Q-7

Q-1

Figure 8: Hysteresis curves of specimens. The hysteretic response of (a) Q-1; (b) Q-1 and Q-2; (c) Q-1 and Q-5; (d) Q-1 and Q-7.

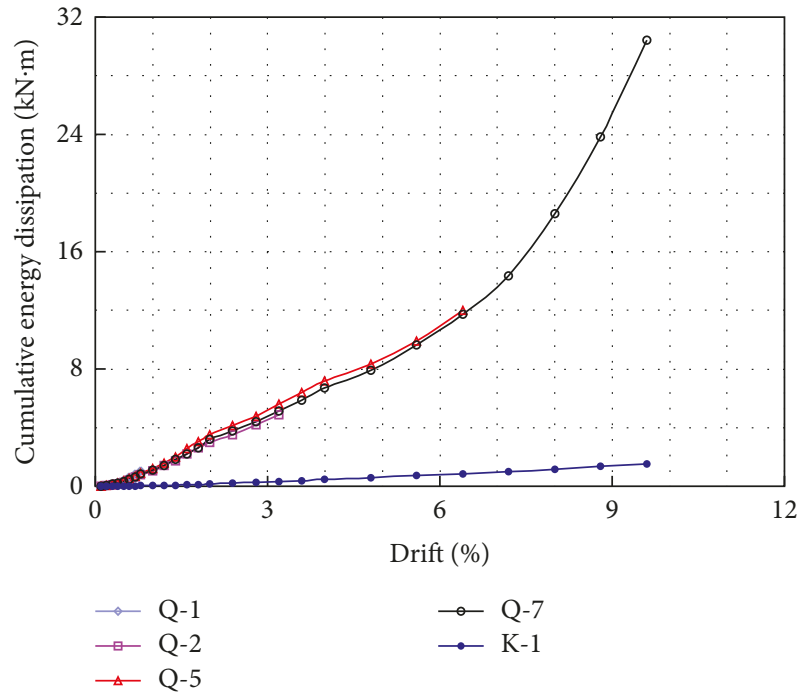

FIGURE 9: Comparison of cumulative energy dissipation of specimens. tie columns and walls was effective on significantly improving the capacity of the energy dissipation. The energy dissipation capacity of each rammed earth wall specimen was similar at the same drift, which indicated that the energy was mainly dissipated by rammed earth.

4.2. Skeleton Curves. The comparison of skeleton curves of the RE walls is shown in Figure 10. The skeleton curve of Specimen Q-1 shows a peak load at a drift ratio of $0.2 \%$ and rapid degradation in strength properties with increasing displacement, which indicates that Specimen Q-1 did not perform as well as other three walls in terms of bearing capacity and deformability capacity. The strength of specimens Q-2, Q-5, and Q-7 reached peak load almost simultaneously at a drift ratio of $1.2 \%$. Specimen Q-2 did not perform as well as Specimens Q-5 and Q-7, showing that wire ties are more effective than tie beam on enhancing deformation capacity. Finally, it could be concluded that the 


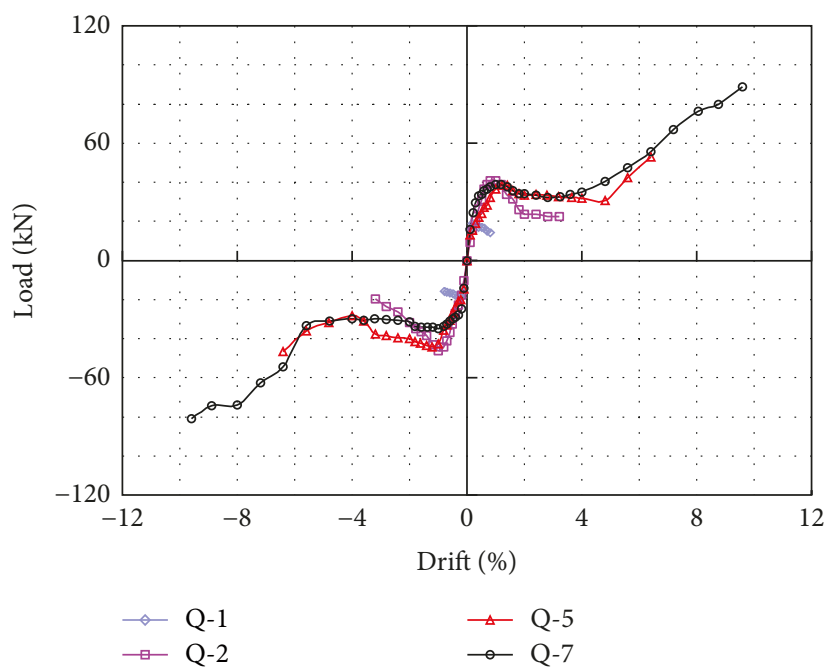

FIGURE 10: Comparison of skeleton curves of specimens.

TABLE 4: Global displacement ductility values of test specimens.

\begin{tabular}{|c|c|c|c|c|c|c|c|c|c|}
\hline \multicolumn{2}{|c|}{ Parameter } & \multirow{2}{*}{$\begin{array}{c}P_{\mathrm{y}}(\mathrm{kN}) \\
18.78\end{array}$} & \multirow{2}{*}{$\frac{\Delta_{\mathrm{y}}(\mathrm{mm})}{1.39}$} & \multirow{3}{*}{$\begin{array}{c}P_{\max }(\mathrm{kN}) \\
18.78 \\
-19.04\end{array}$} & \multirow{3}{*}{$\begin{array}{c}\Delta_{\max }(\mathrm{mm}) \\
2.40 \\
-2.40\end{array}$} & \multirow{3}{*}{$\begin{array}{c}P_{\mathrm{u}}(\mathrm{kN}) \\
15.96 \\
-16.18\end{array}$} & \multirow{3}{*}{$\begin{array}{c}\Delta_{\mathrm{u}}(\mathrm{mm}) \\
7.62 \\
-8.09\end{array}$} & \multirow{3}{*}{$\begin{array}{c}\mu=\Delta_{\mathrm{u}} / \Delta_{\mathrm{y}} \\
5.48 \\
5.99\end{array}$} & \multirow{3}{*}{$\frac{\text { Mean value of } \mu}{5.74}$} \\
\hline & POS & & & & & & & & \\
\hline$Q-1$ & NEG & -16.65 & -1.35 & & & & & & \\
\hline \multirow{2}{*}{ Q-2 } & POS & 26.14 & 4.77 & 40.73 & 9.60 & 34.62 & 16.24 & 3.40 & \multirow{2}{*}{3.27} \\
\hline & NEG & -29.09 & -5.21 & -46.25 & -12.00 & -39.31 & -16.35 & 3.14 & \\
\hline \multirow{2}{*}{ Q-5 } & POS & 25.84 & 5.58 & 38.40 & 16.80 & 32.64 & 38.83 & 6.96 & \multirow{2}{*}{6.82} \\
\hline & NEG & 26.29 & -5.76 & -44.35 & -14.40 & -37.70 & -38.47 & 6.68 & \\
\hline \multirow{2}{*}{ Q-7 } & POS & 30.99 & 4.17 & 38.87 & 12.00 & 33.04 & 29.81 & 7.15 & \multirow{2}{*}{7.93} \\
\hline & NEG & -28.58 & -4.30 & -35.07 & -12.00 & -29.81 & -37.43 & 8.70 & \\
\hline
\end{tabular}

Note. POS: positive direction; NOG: negative direction. $P_{\mathrm{y}}$ : the yield load; $\Delta_{\mathrm{y}}$ : the displacement corresponding to the yield load; $P_{\max }$ : the peak load; $\Delta_{\max }$ : the displacement corresponding to the peak load; $\Delta_{\mathrm{u}}$ : determined as corresponding to a $15 \%$ drop of the peak load; $P_{\mathrm{u}}$ : the load corresponding to $\Delta_{\mathrm{u}}$.

proposed precast concrete tie columns are effective on dramatically improving the performance of the seismic and deformability.

4.3. Ductility Capacity and Bearing Capacity. The ductility capacity is identified as an important parameter for earthquakeresistant constructions, which could be calculated as the ratio of ultimate displacement to the yield displacement. Using the ultimate displacement and calculated yield, the ductility capacity value is determined as follows:

$$
\mu=\frac{\Delta_{\mathrm{u}}}{\Delta_{\mathrm{y}}}
$$

where $\Delta_{\mathrm{u}}$ is determined as corresponding to a $15 \%$ drop of the peak load and $\Delta_{\mathrm{y}}$ is the displacement corresponding to the yield load.

The peak load, the ultimate displacement, the yield load, the yield displacement, and ductility value of the test walls are presented in Table 4 . Although the ductility value of Specimen Q-2 was slightly lower than that of Specimen Q-1, the deformation capacity of Specimen Q-2 was significantly higher than that of Specimen Q-1. The ductility value of Specimens Q-5 and Q-7 is $18.79 \%$ and $38.1 \%$ higher than that of Specimen Q-1, respectively, which shows that the application

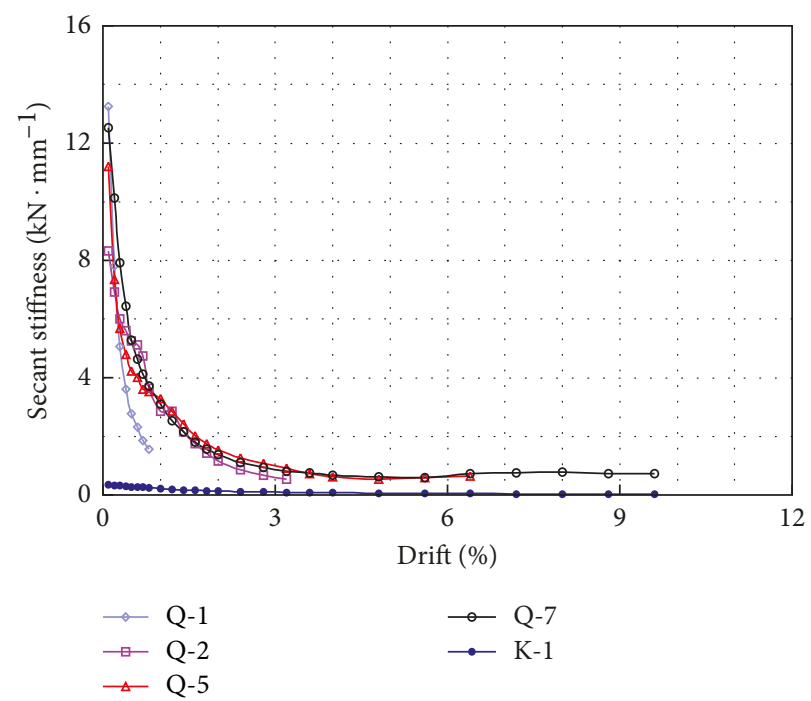

FIgURE 11: Stiffness degeneration curves.

of precast concrete tie columns and precast concrete tie beam (wire ties) could significantly improve the deformation capacity of the test walls. The ductility value of Specimens Q-7 is $16.28 \%$ higher than that of Specimen Q-5, attributed to the increase in the number of wire ties. 


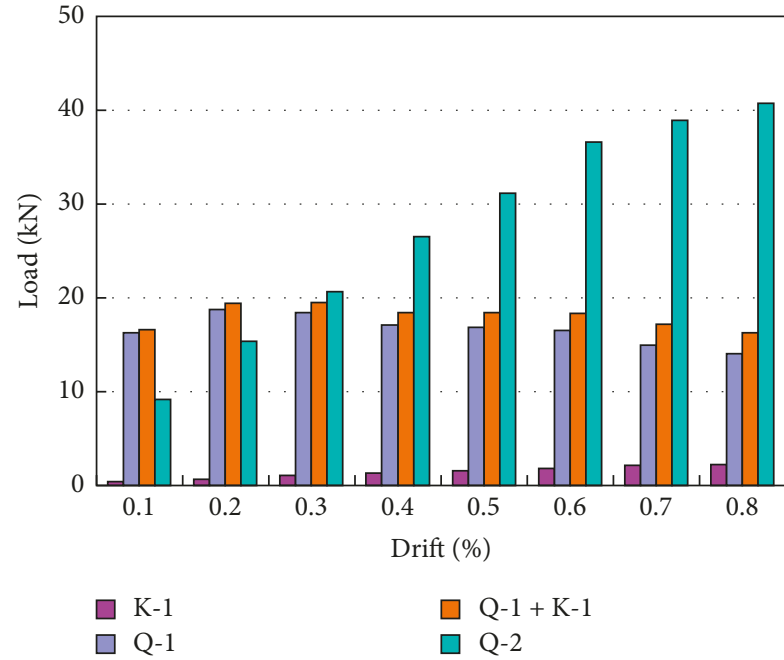

(a)

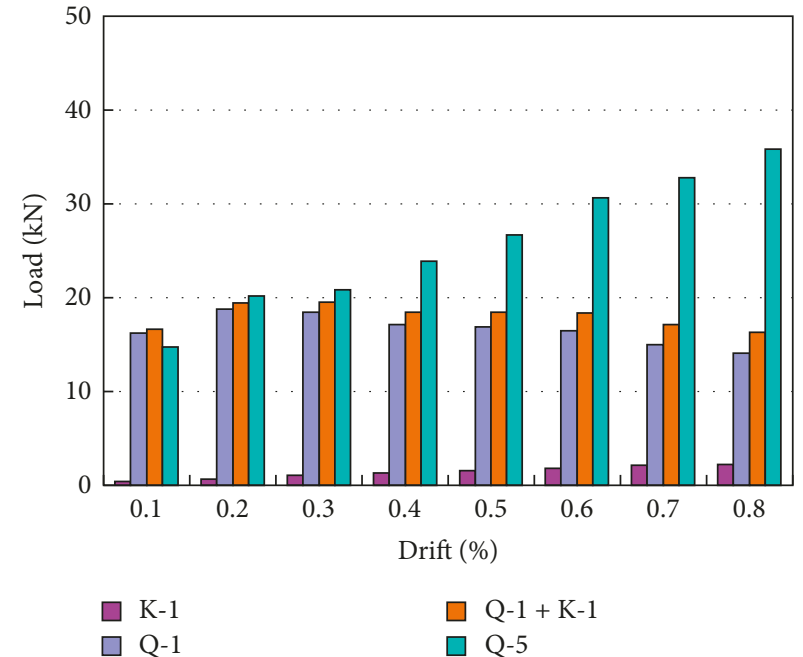

(b)

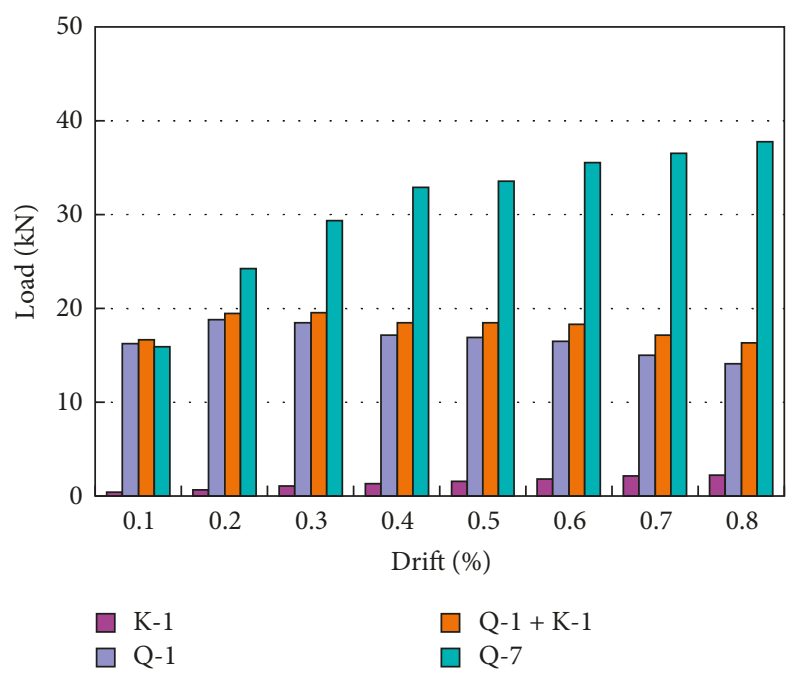

(c)

FIGURE 12: Comparison of strength of specimens at specific drifts. Comparison of strength between (a) Q-2 and Q-1; (b) Q-5 and Q-1; (c) Q-7 and Q-1.

The result clearly shows that the yield load and the yield displacement of Specimens Q-2, Q-5, and Q-7 are significantly higher than control Specimen Q-1. Compared with control Specimen Q-1, the ultimate bearing capacity of other three specimens was increased by $95 \% \sim 130 \%$, which were confined by precast concrete tie columns and precast concrete tie beam (wire ties). The maximum bearing capacity of Specimen Q-2 is the largest among four wall specimens, and the maximum bearing capacity of Specimen Q-5 was similar to that of Specimen Q-7, showing that effect of the precast concrete tie beam is better than that of tie bars in terms of maximum bearing capacity.

4.4. Stiffness Degeneration. Stiffness degradation is one of the most important criteria for evaluating the performance of test walls, when subjected to simulated lateral earthquake loading in successive low-rate reversed cycles. The stiffness at different cycles was determined using (2). This calculation only involves the first reversal cycle. The comparison of stiffness degradation for all specimens is shown in Figure 11.

$$
K_{i}=\frac{\left|+P_{i}\right|+\left|-P_{i}\right|}{\left|+\Delta_{i}\right|+\left|-\Delta_{i}\right|}
$$

The initial stiffness of the confined walls (Q-2, Q-5, and Q-7) is close to that of the control specimen, Q-1, which is attributed to low lateral stiffness of the frame (K-1). The secant stiffness of Specimen Q-1 is only approximately $40 \%$ of the other three walls at a drift ratio of $0.8 \%$. The walls confined by precast concrete tie columns had a lower rate of stiffness degradation compared to Specimen Q-1, attributed to the restriction from precast concrete tie columns and precast concrete tie beam (wire ties).

4.5. The Influence of Tie Column and Tie Beam (Wire Ties). Figure 12 shows a comparison of bearing capacity of 
five specimens at different drifts. "Q-1 $+\mathrm{K}-1$ " denotes the summation of the bearing capacity of Specimens K-1 and Q-1 at the specific drift. Because the test of specimen Q-1 was terminated at a drift ratio of $0.8 \%$, it is assumed that the subsequent bearing capacity remains constant.

Referring to Figure 12, it can be seen that there is little difference between the bearing capacity of Specimens Q-2, $\mathrm{Q}-5$, and "Q-1 + K-1" when the drift is not beyond $0.3 \%$, which shows that the action of two precast concrete tie columns and one precast concrete tie beam (wire tie) is weak. The bearing capacity of Specimen Q-7 is bigger than that of "Q-1 + K-1," and this could be due to the fact that there are three wire ties; therefore, the combined action of two precast concrete tie columns and three wire ties is stronger than that of one wire ties. On the whole, the effect of precast concrete tie columns and precast concrete tie beam (wire ties) on the bearing capacity is not obvious at the initial stage of loading. When the story drift is beyond $0.3 \%$, the effect of precast concrete tie columns and precast concrete tie beam (wire ties) on the bearing capacity is more and more obvious as the story drift increases.

\section{Conclusions}

Four rammed earth walls were tested under lateral cyclic loading, and the seismic performance were discussed in terms of bearing capacity, stiffness degradation, and displacement ductility, and so on. Based on the results of this investigation, the following conclusions could be drawn:

(1) A majority of cracks were observed in the middle section of the wall attributed to the low shear strength in layers. Hence, it is necessary to consider the possibility of split-level construction and pin keys to improve the shear strength.

(2) The proposed construction measures are effective on significantly improving the performance of bearing capacity and deformability.

(3) The effect of precast concrete tie columns and precast concrete tie beam (wire ties) on the bearing capacity is not obvious at the initial stage of loading; however, when the story drift is beyond $0.3 \%$, the effect is significant.

(4) In general, the application of wire ties instead of a tie beam is practical and effective, and the number of wire ties has an effect on the seismic performance of the RE walls.

\section{Conflicts of Interest}

The authors declare that there are no conflicts of interest regarding the publication of this paper.

\section{Acknowledgments}

This work was supported by Ministry of Science and Technology of the People's Republic of China (Grant no. 2015BAL03B02).

\section{References}

[1] R. Kumar, S. Sachdeva, and S. C. Kaushik, "Dynamic earthcontact building: a sustainable low-energy technology," Building and Environment, vol. 42, no. 6, pp. 2450-2460, 2007.

[2] M. I. Gomes, M. Lopes, and J. D. Brito, "Seismic resistance of earth construction in Portugal," Engineering Structures, vol. 33, no. 3, pp. 932-941, 2011.

[3] H. Binici, O. Aksogan, and T. Shah, "Investigation of fiber reinforced mud brick as a building material," Construction and Building Materials, vol. 19, no. 4, pp. 313-318, 2005.

[4] A. P. da Silva Milani and L. C. Labaki, "Physical, mechanical, and thermal performance of cement-stabilized rammed earth-rice husk ash walls," Journal of Materials in Civil Engineering, vol. 24, no. 6, pp. 775-782, 2012.

[5] B. V. Venkatarama Reddy and P. Prasanna Kumar, "Structural behavior of story-high cement-stabilized rammed-earth walls under compression," Journal of Materials in Civil Engineering, vol. 23, no. 3, pp. 240-247, 2011.

[6] H. Niroumand, M. F. M. Zain, and M. Jamil, "The role of nanotechnology in rammed earth walls and earth buildings," Procedia-Social and Behavioral Sciences, vol. 89, pp. 243-247, 2013.

[7] B. V. Venkatarama Reddy and P. Prasanna Kumar, "Cement stabilised rammed earth. Part B: compressive strength and stress-strain characteristics," Materials and Structures, vol. 44, no. 3, pp. 695-707, 2011.

[8] J. S. J. Cheah, P. Walker, A. Heath, and T. K. K. B. Morgan, "Evaluating shear test methods for stabilised rammed earth," Proceedings of the Institution of Civil Engineers-Construction Materials, vol. 165, no. 6, pp. 325-334, 2012.

[9] M. Bouhicha, F. Aouissi, and S. Kenai, "Performance of composite soil reinforced with barley straw," Cement and Concrete Composites, vol. 27, no. 5, pp. 617-621, 2005.

[10] Q.-B. Bui, J.-C. Morel, S. Hans, and P. Walker, "Effect of moisture content on the mechanical characteristics of rammed earth," Construction and Building Materials, vol. 54, no. 15, pp. 163-169, 2014.

[11] Y.-H. Bu, Y.-H. Wang, G. Han, and L. Li, "Experimental study on seismic behavior of raw-soil structure with rammed earth walls by different construction methods," Journal of Chang'an University, vol. 31, no. 6, pp. 72-76, 2011. 


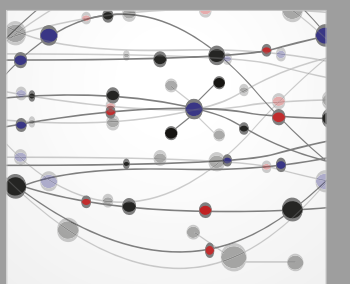

The Scientific World Journal
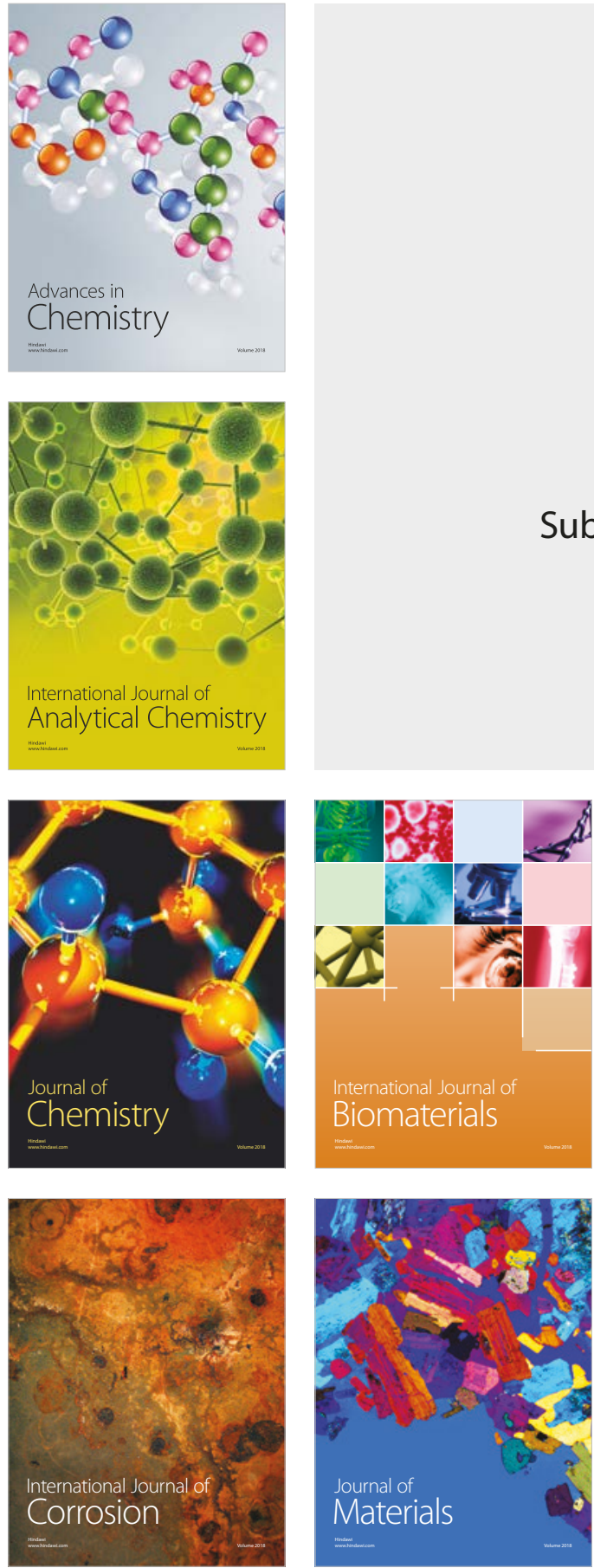

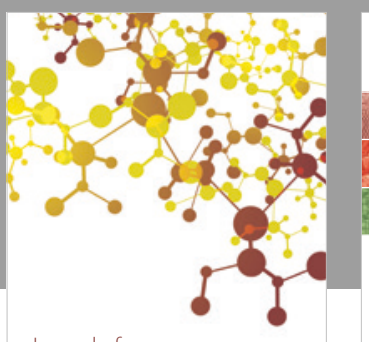

Journal of

Applied Chemistry
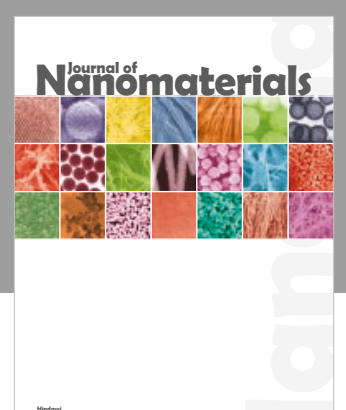

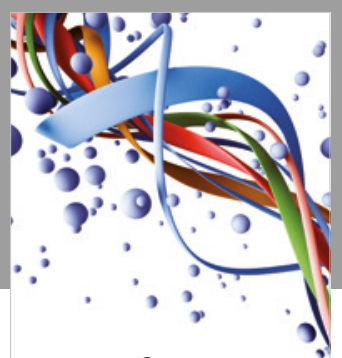

Scientifica

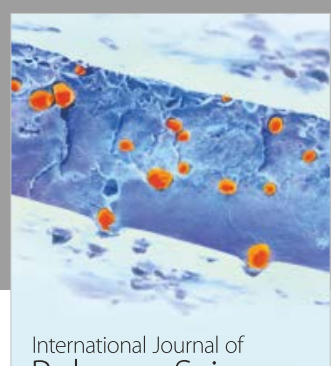

Polymer Science

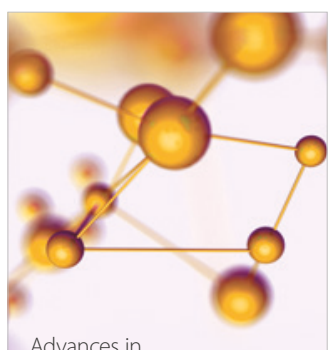

Physical Chemistry
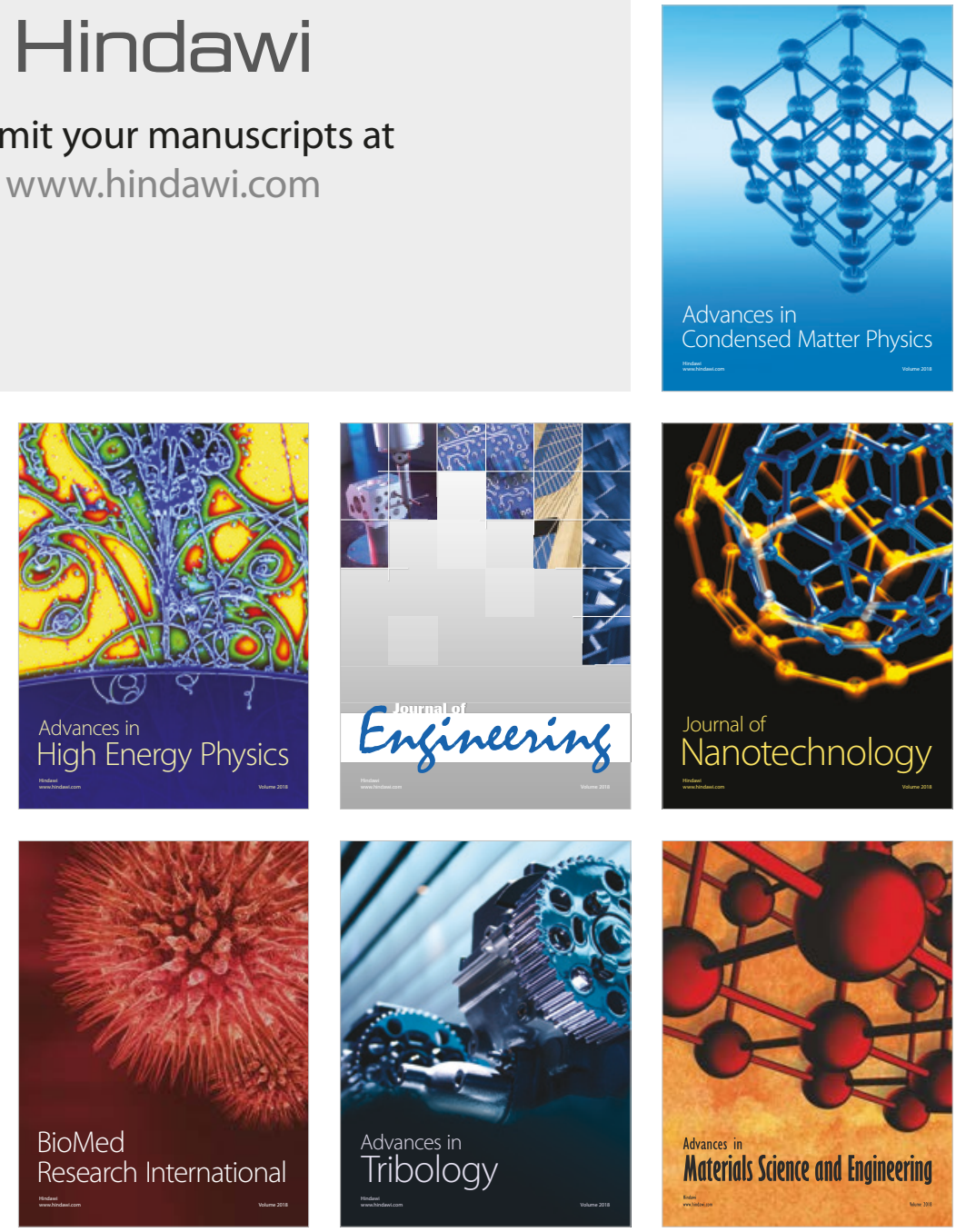